\title{
Mysid population responses to resource limitation differ from those predicted by cohort studies
}

\author{
Jason S. Grear*, Doranne Borsay Horowitz, Ruth Gutjahr-Gobell
}

Atlantic Ecology Division, National Health and Environmental Effects Research Laboratory, Office of Research and Development, US Environmental Protection Agency, Narragansett, Rhode Island 02882, USA

\begin{abstract}
Effects of anthropogenic stressors on animal populations are often evaluated by assembling vital rate responses from isolated cohort studies into a single demographic model. However, these models are difficult to translate into ecological predictions because stressor effects observed in isolated cohorts may differ from those occurring in populations with overlapping generations. This problem is evident in many areas of stressor-response research, including the burgeoning work on ocean acidification. To address this problem, we compared vital rates in experimental cohorts and populations of the mysid Americamysis bahia at 4 levels of resource limitation. This required development of a novel observational scheme that allows inverse estimation of stage-specific vital rates in mixed-age populations without the use of cohort isolation or marking. Using digitally imaged time series observations of stage abundances, the most strongly supported inverse models indicated opposing (i.e. compensatory) effects of resource limitation on adult survival and juvenile maturation. The model with adult survival response only (i.e. no compensation) was also strongly supported. This contrasts with cohort results, where feeding effects on fecundity were strongest. These results suggest that emphasis in stressor-response studies on early life stages and cohorts of uniformly aged individuals may miss important demographic responses and should be augmented by observations of intact populations, especially as methods such as ours become more available.
\end{abstract}

KEY WORDS: Inverse demography - Zooplankton • Population model • Cohort • Survival • Americamysis bahia

- Resale or republication not permitted without written consent of the publisher

\section{INTRODUCTION}

Most observations of stressor effects on marine crustaceans are made on individuals or even-aged cohorts. Results of these cohort studies are difficult to translate into ecological predictions, either because the importance of the impaired trait to the overall life cycle is unknown or because stressor effects on complex populations may differ from those observed in simplified cohorts. Current examples of this problem occur in ecological risk assessment of chemicals and analyses of ocean acidification scenarios, where investigators have acknowledged the need for life cycle approaches in predicting adaptive responses to changing environments (Fabry et al. 2008, Ries et al. 2009).

Stressor-response studies often resort to cohortbased approaches because of difficulties in determin- ing ages, births and deaths in populations with overlapping generations. In cases where marking of individuals or groups is not feasible, cohort analyses address this problem by isolating and tracking the fates of single or multiple individuals from birth. This enables a sharp focus on biological mechanisms underlying individual responses, but applicability of results to field settings or mixed-age laboratory populations is usually unknown. A common approach for bridging this gap is to substitute impaired vital rates into population models that contain stage structure but are themselves constructed using vital rates from disparate data or additional cohort studies (i.e. matrix element substitution; Caswell 2001, Morris \& Doak 2002). Changes in population-level attributes predicted by the model (e.g. population growth rate) are then used in expressions of ecological risk. Much literature has 
now accumulated from such studies and has enabled meta-analytic reviews of general life history patterns and vital rate responses to large-scale stressors (e.g. Forbes et al. 2010, Hendriks et al. 2010). It is unclear whether the conclusions from these reviews are affected by reliance on cohort studies and matrix substitution analyses. If so, implications for prediction of extinction risk, loss of biodiversity and ecosystem change are significant. In our study of the mysid Americamysis bahia, we compared results from this substitution approach with analyses of observations on whole populations, where matrix models were parameterized using inverse estimation from stagestructured time series observations. Our comparison focused on demographic responses to resource limitation, which is a common complication in applied population ecology.

Mysids are peracarid crustaceans that include $>1000$ species from freshwater and marine environments. Americamysis bahia (formerly Mysidopsis bahia) is commonly used as a test organism in ecotoxicology (reviewed in Verslycke et al. 2007), so substantial effort has been devoted to the standardization of laboratory culturing methods and production of uniformly conditioned individuals (Lussier et al. 1988, Kuhn et al. 1991). Individuals are 5 to $10 \mathrm{~mm}$ in length (rostrum to telson). A. bahia is an abundant epibenthic species in nearshore waters of the Gulf of Mexico but is also found along the Atlantic seaboard of North America as far north as Rhode Island (Heard et al. 2006). Mysids are considered primarily omnivorous with diets that may include organic detritus, but stomach content studies have suggested carnivorous or planktivorous diets in certain species, places or seasons (Mauchline 1980). Although mysids are abundant throughout the world's oceans and are known to be consumed by many fish species, Jumars (2007) argued that their ecological importance has been underestimated because of sampling limitations.

Most ecological knowledge about Americamysis bahia comes from laboratory studies. In addition to the many studies of chemical lethality, cohort-based observations of A. bahia stress responses have been combined with matrix element substitution to predict effects on abundance or population growth rate (Kuhn et al. 2000, 2001, Raimondo \& McKenney 2005). Similarly, Gentile et al. (1982) used Euler-Lotka formulations to estimate population growth rate from A. bahia cohort data. Although demographic model projections were tested by Kuhn et al. (2001) using observations of total population size, estimation of specific vital rates within these intact populations was not possible. Markert et al. (2010) used scalar density-dependent models to separate genetic diversity and resource effects on A. bahia population size. However, because food limitation was intentionally eliminated, density dependence was likely related to spatial limitation in the aquariums used in that study. Our goals were to extend these studies by using life cycle responses rather than total population size as an endpoint and to demonstrate differences in conclusions that can arise from cohort-based versus population-based approaches. Specifically, we tested whether resource effects on reproduction and survival in the cohort experiments were predictive of those observed in our population experiments. We also examined whether substitution of cohort results into matrix models accurately depicted the relative importance of each vital rate to fitness responses in the population experiments.

\section{MATERIALS AND METHODS}

We manipulated feeding rate in both cohort-based and population-based experiments. The cohort experiments provided a basis for comparison with the population study and also allowed estimation of size-at-age relationships that were used to delineate stages in the inverse demographic analysis. All experiments were conducted in the seawater laboratory at the US EPA's Atlantic Ecology Division (AED) on the west shore of Narragansett Bay, Rhode Island.

Cohort experiments. We measured Americamysis bahia mortality, size and neonate production in 16 glass seawater aquaria (9.5 l) fitted with screened overflow outlets. Each aquarium was initiated on Day 0 with $25 \mathrm{~A}$. bahia neonates of 1 to $2 \mathrm{~d}$ old. This relatively low density, maintained throughout the experiment, was intended to assure the absence of spatial resource competition. Neonates were obtained from laboratory cultures at AED using the spawning chamber technique described in Lussier et al. (1988). Additional neonates were set aside on Day 0 for the setup of parallel aquariums for restocking of the experimental aquariums (see below). All aquaria were maintained in seawater baths at $24^{\circ} \mathrm{C}$, ambient seawater salinity and a $12 \mathrm{~h}$ day: $12 \mathrm{~h}$ night cycle. Five times per week, we established seawater inflow to all aquaria simultaneously at a rate of $125 \mathrm{ml} \mathrm{min}^{-1}$ for approximately $1 \mathrm{~h}$.

Our 16 aquaria were arrayed in 4 randomized complete blocks of 4, with Block 1 initiated on 11 July 2008, Block 2 initiated on 23 July 2008 and Blocks 3 and 4 initiated on 11 September 2008. Each block received all treatments, so temporal staggering of blocks should not impact treatment effects. One aquarium in each block was assigned one of 4 nominal feeding rates: 1000, 2000, 3000 or 4000 Artemia d $^{-1}$, which translates to $40,80,120$ and 160 Artemia nauplii mysid ${ }^{-1} \mathrm{~d}^{-1}$ given the estimated density of $1000 \mathrm{ml}^{-1}( \pm 345 \mathrm{SD})$ in the Artemia suspension. These rates were designed to 
bracket the optimal feeding rate seen in previous studies (R. Gutjahr-Gobell unpubl. data; also see Kuhn et al. 1991) for mysids 3 to $12 \mathrm{~d}$ old (90 Artemia mysid ${ }^{-1}$ $\mathrm{d}^{-1}$ ). We used a $10 \mathrm{ml}$ pipette to transfer the appropriate volume of Artemia suspension into each aquarium, although variation was likely introduced by daily variation in those suspensions and by our pipette method. On weekdays, the daily feeding amount was divided into morning and afternoon portions.

On Days 7, 14, 21 and 28, we decanted seawater from the aquaria and transferred the contents to Pyrex bowls. Over a backlit table, mysids were counted and removed from the seawater, which was discarded along with any accumulated detritus. Neonates were present in counts that occurred on Days 21 and 28 (i.e. at the ends of Weeks 3 and 4) and were easily distinguishable from the study cohorts because of the difference in size. To eliminate effects of mysid abundance on per capita resource density, we maintained constant spatial density by removing neonates and, in cases where mortality was recorded (i.e. cohort count <25), replacing dead mysids with identically aged individuals from the stock aquaria. On average, each aquarium received a total of 3.4 replacement mysids (i.e. less than $14 \%$ of each cohort) throughout the course of the experiment (i.e. on Days 7, 14 and 21 combined), so we assume replacements had no effect on cohort characteristics.

After counting and removal of neonates on Days 7 , 14, 21 and 28, we placed each cohort in a $10 \times 10 \times 1 \mathrm{~cm}$ vertically positioned cast acrylic observation chamber filled with seawater. We backlit the chamber with an upright light source and captured digital images of the horizontal view into the $10 \times 10 \mathrm{~cm}$ front surface of the chamber. We used a Pixelink PLB771G machine vision camera with a $60 \mathrm{~mm}$ Nikon lens and measured the full length of each individual (tip of uropod to tip of antennal scale) in captured images using ImageJ image processing software (Rasband 2009).

We analyzed feeding treatment effects on neonate production by fitting generalized linear mixed-effects models with Poisson-distributed error (R Development Core Team 2008; lme4 package) to neonate count data (counts from weeks when cohorts were immature were not included). Cohort age and feeding rate were treated as fixed effects. Because neonates were counted twice in each aquarium (i.e. at cohort ages 3 and $4 \mathrm{wk}$ ), aquarium identity was included in the model as a random effect. We used likelihood and corrected Akaike's information criterion $\left(\mathrm{AIC}_{\mathrm{c}}\right.$ ) (Burnham \& Anderson 2002) to assess support for models containing fixed effects. Statistical analysis of survivor counts in the cohort study was identical to neonate analysis, except that we used a logit-linked binomial model and did not exclude counts taken at ages 1 and 2 wk. Estimates from these response models were then used to construct age-based matrix models specific to each feeding rate. This allowed visualization of vital rate contributions to projected population-level response using life table response (LTRE) analysis (Caswell 2001). In this approach, contributions are approximately the product of each vital rate $(p)$ sensitivity in the mean matrix model $(\partial \lambda / \partial p$, where $\lambda$ is the population growth rate) and deviation $\left(p_{i}-\bar{p}\right)$ of the vital rate at treatment $i$ (see Caswell 1989, 2001 for calculation details).

We fit von Bertalanffy growth models to lengths of the individuals of known age in the cohort study using least squares (R Development Core Team 2008; PBSmodelling package). This model predicted length at age $x\left(L_{x}\right)$ using $L_{x}=\alpha+\beta \rho^{x}$, where $\alpha, \beta$ and $\rho$ are free parameters. We assessed support for feeding rate effects on size-at-age by using AIC to compare growth models with and without treatment effects.

Population experiments. We initiated 8 populations on each of 3 dates-11 February, 27 February and 13 March 2009 - for a total of 24 populations. The resulting 3 blocks of populations were set up and maintained under the same conditions as the cohort experiments, except that densities were not controlled by removing neonates or replacing dead individuals. Populations were initiated with 25 individuals but were allowed to stabilize for 6 to $8 \mathrm{wk}$ before feeding treatments were imposed. Data from the stabilization period were excluded from the analyses. In a randomized complete block design initiated within $24 \mathrm{~h}$ after the 22 April 2009 weekly count, we randomly assigned one of 4 feeding rates to 2 aquaria in each block for an experiment-wide replication rate of 6 aquaria per treatment. Feeding treatments were nominally designated as 4, 6 , 8 and $10 \mathrm{ml}$ of an Artemia nauplii suspension given to each aquarium each day. During weekdays, these amounts were split into a morning and afternoon feeding. Given an estimated Artemia density of 750 nauplii $\mathrm{ml}^{-1}( \pm 355 \mathrm{SD})$ during this experiment, this translates to nominal treatments of 3000,4500, 6000 and 7500 Artemia aquarium ${ }^{-1} \mathrm{~d}^{-1}$. Culturing recommendations in Lussier et al. (1988) suggest that densities of 10 to 15 mysids $\mathrm{l}^{-1}$ (i.e. $~ 90$ to 135 mysids aquarium ${ }^{-1}$ ) are possible. At 100 mysids per aquarium, our feeding treatments would translate to 30,45, 60 and 75 Artemia mysid $^{-1} \mathrm{~d}^{-1}$. However, Markert et al. (2010) observed stable abundances closer to 50 individuals per aquarium in the same seawater laboratory we used. At this density, which resembles the densities we observed (see 'Results'), our treatments would translate to 60, 90, 120 and 150 Artemia mysid ${ }^{-1} \mathrm{~d}^{-1}$. These estimates are within the ranges used in the cohort experiment.

In our weekly censuses, we used the same digital imaging techniques as in the cohort experiment. However, rather than using single images for each popula- 
tion, we obtained sequences of 250 frames at a rate of 10 frames $\mathrm{s}^{-1}$. These sequences were analyzed in ImageJ (Rasband 2009) by subtracting the averaged sequence from the first image in the sequence. The process serves to remove non-moving objects and chamber surface impurities from the resulting image, which we then converted to a binary image for application of ImageJ's built-in particle analyzer. In a final user-guided step, we checked for occluded individuals by manually advancing frames in the original video sequence, corrected errant particle delineations and then exported the confirmed particle lengths for further analysis. These censuses were repeated each week from 22 April to 24 June 2009, resulting in 10 censuses and a total of 8922 length measurements.

We found evidence for feeding rate effects on sizeat-age in the cohort study (see 'Results'). We suspected that this was related to food availability per mysid, which would vary with mysid abundance in our population study. Rather than trying to build densitydependent size-at-age models for age classification, we first assigned mysids to size-based stages by determining weekly length breakpoints from the simplest von Bertalanffy curve in the cohort study (i.e. the reduced model). These breakpoints were length < $1.67 \mathrm{~mm}$, for neonates; $1.67 \mathrm{~mm} \leq$ length $<5.07 \mathrm{~mm}$ for juveniles; and length $\geq 5.07 \mathrm{~mm}$ for adults. Prior to further analysis, we collapsed the data for each population into a $10 \mathrm{wk}$ time series of stage abundances. As described in greater detail below, treatment effects on growth were then accommodated by including stagebased matrix models with treatment-dependent stage transitions in our model suite for inverse demographic estimation. Because of the strong relationship between size and reproduction reported by Lussier et al. (1991), we viewed growth transition into the larger adult stage as a maturation process.

We hypothesized 28 biologically plausible responses of mysid demography to feeding treatments (see Table 3). These hypotheses were formulated by building linear response models for specific parameters into the stage-based projection matrix:

$$
\mathbf{A}_{j}=\left[\begin{array}{ccc}
P_{1} & 0 & F \\
G_{1} & P_{2} & 0 \\
0 & G_{2} & P
\end{array}\right]
$$

where $P_{i}$ is survival within stage $i, G_{i}$ is survival and transition into age or stage $i+1, P$ is adult survival, $F$ is the per capita production of neonates at time $t$ by adults alive at time $t-1$, and $\mathbf{A}_{j}$ denotes the projection matrix for the $j$ th treatment level. The stage-based formulation of $\mathbf{A}$ allows delayed size-class transition of survivors (Caswell 2001), thereby accommodating the treatment effects on size-class transitions suggested by our cohort study results. For neonates and juveniles, this is accomplished in our estimation procedure by specifying total survival $\left(S_{i}=P_{i}+G_{i}\right)$ and transition rate $(\gamma)$ as logit-linear functions with $T$ denoting feeding rate:

$$
\begin{aligned}
& S_{i, j}=1 /\left\{1+\exp \left[-\left(\beta_{S, 0}+\beta_{S, 1} T_{j}\right)\right]\right\} \\
& \gamma_{i, j}=1 /\left\{1+\exp \left[-\left(\beta_{\gamma, 0}+\beta_{\gamma, 1} T_{j}\right)\right]\right\} \\
& G_{i, j}=S_{i, j} \gamma_{i, j} \\
& P_{i, j}=S_{i, j}\left(1-\gamma_{i, j}\right)
\end{aligned}
$$

Adult survival $(P)$ was modeled as a single logitlinear function with parameters $\beta_{P, 1}$ and $\beta_{P, 2}$. Treatment effects on fecundity $(F)$ were modeled with a simple linear function:

$$
F_{i, j}=\beta_{F, 0}+\beta_{F, 1} T_{j}
$$

Our 28 life cycle response hypotheses were then formulated as varying constraints on these functions during maximum likelihood estimation. For example, age-based versions were produced by setting all $\gamma$ terms to one, which forces $P_{1}$ and $P_{2}$ to zero. A model without treatment effects constrains all slope parameters to zero $\left(\beta_{S, 1}=\beta_{\gamma, 1}=\beta_{F, 1}=\beta_{P, 1}=0\right)$.

We fit these demographic models to our stage abundance time series by adapting a multivariate maximum likelihood estimation method described in Dennis et al. (1995) and summarized by Caswell (2001) (see Wood 1994 for an alternative method). The approach exploits the lognormal error structure common to stochastic population time series. First, we denote our time series using $\mathbf{n}_{i, j, t}$, which is the population vector of the $i$ th population replicate of the $j$ th treatment level at time $t$. The main distinction in our approach is in our state transition equation:

$$
\ln \mathbf{n}_{i, j, t+1}=\ln \left(\mathrm{A}_{j} \mathbf{n}_{i, j, t}\right)+E_{i, j, t}
$$

where $E_{i, j, t}$ has a multivariate normal distribution with mean $=0$ and covariance $=\Sigma_{i}$. The first term on the right side of our Eq. (4) replaces the $\boldsymbol{h}$ transition function for the Tribolium model in Eq. (19) of Dennis et al. (1995). The differences between the observed $\left(\mathbf{n}_{i, j, t}\right)$ and expected stage abundances $\left(\hat{\mathbf{n}}_{i, j, t}\right)$ were treated as lognormal stochasticity. For each model, we used a single $\Sigma$ (i.e. one $3 \times 3$ covariance matrix common to all populations). We maximized the log likelihoods for each demographic response model using nonlinear optimization (SAS/IML software; SAS Institute 2008). Support for each model was assessed using $\mathrm{AIC}_{\mathrm{C}}$ (Burnham \& Anderson 2002).

Our 28 demographic response models included 10 age-based and 18 stage-based formulations (see Table 3). Within each of these groups, there was a no effects model (reduced) and all possible single effects models (e.g. feeding effect on $F, G_{1}, G_{2}$, or $P$ ). In addition, there were 4 paired effects models in the age- 
based group (feeding effects on $P+G_{1}, P+G_{2}, P+F_{\text {, }}$ $F+G_{1}$ and $F+G_{2}$, where ' + ' denotes inclusion in the model rather than addition). There were 11 such models in the stage-based group $\left(P+S_{1}, P+S_{2}, P+\gamma_{1}, P+\right.$ $\gamma_{2}, P+F, F+S_{1}, F+S_{2}, F+\gamma_{1}, F+\gamma_{2}, S_{1}+\gamma_{1}$ and $\left.S_{2}+\gamma_{2}\right)$. The models with multiple effects were intended to allow for demographic compensation, but the signs $(+/-)$ of the responses were not constrained. Other potential multiple effects models were not included when we could not envision a simple interpretation or basis in life history theory.

Our results indicated support for several of the demographic response models (see 'Results'). Thus, we incorporated model selection uncertainty using model averaging (Burnham \& Anderson 2002), whereby each model's contribution to the final parameter estimates $\left(\hat{S}_{1}, \hat{\gamma}_{1}, \hat{S}_{2}, \hat{\gamma}_{2}, \hat{F}, \hat{P}\right)$ is governed by the $\operatorname{AIC}_{\mathrm{c}}$ weight $(w)$ of that model (see Table 3 ). After deriving these modelaveraged parameter estimates, we used LTRE analysis to visualize the contribution of each vital rate response to population-level effects and to allow comparison with the cohort-based LTRE.

\section{RESULTS}

\section{Cohort experiments}

Based on $\mathrm{AIC}_{\mathrm{C}}$, the best model for neonate count in our cohort study included both feeding rate and age (Table 1). This model included strong positive age and feeding effects and a small negative age $\times$ feeding rate interaction (Table 1, Fig. 1). During the fourth week, the lowest feeding rate produced a mean of $85 \%$ fewer neonates than the highest feeding rate (0.14 vs. 0.94 neonates per 25 adults). Feeding effects on survival were weak in the cohort study. The best survival model included age only (Table 2), with survival declining from 0.97 at Week 1 to 0.90 at Week 4 . The second best model included age and feeding rate (no interaction), with estimated survival at Week 4 increasing from 0.90

Table 1. Americamysis bahia. Log-likelihood (log $L)$, number of parameters $(k)$, corrected AIC $\left(\Delta \mathrm{AIC}_{\mathrm{c}}\right)$ and model probability $(w)$ for 5 models of age and feeding effects on mysid neonate counts per aquarium cohort (with Poisson-distributed errors)

\begin{tabular}{|lccrc|}
\hline Model & $\log L$ & $k$ & $\Delta \mathrm{AIC}_{\mathrm{c}}$ & $W$ \\
\hline Age $\times$ Feeding & -54.6 & 5 & 0.0 & 0.98 \\
Age + Feeding & -59.9 & 4 & 7.8 & 0.02 \\
Feeding & -79.1 & 3 & 43.6 & 0.00 \\
Age & -64.0 & 3 & 13.4 & 0.00 \\
Intercept & -83.2 & 2 & 49.4 & 0.00 \\
\hline
\end{tabular}

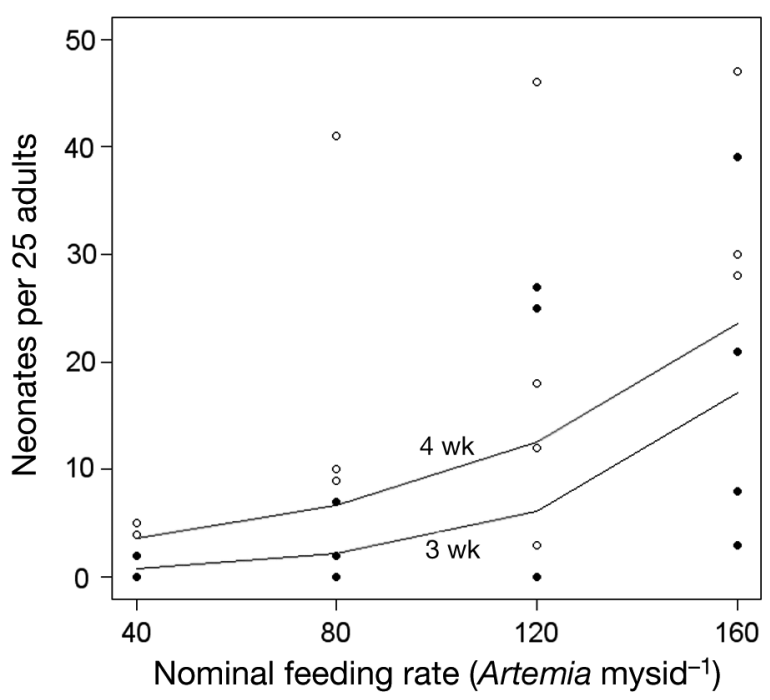

Fig. 1. Americamysis bahia. Observed (points) and predicted (lines) numbers of mysid neonates per aquarium from the Age $\times$ Feeding model with Poisson-distributed errors and aquarium-specific random effects. o: neonates counted at the end of the 3rd week; $\bullet$ : those at the end of the 4th week.

Abundances were maintained at 25 adults per aquarium

Table 2. Americamysis bahia. Log-likelihood (log L), number of parameters $(k)$, corrected AIC $\left(\Delta \mathrm{AIC}_{\mathrm{c}}\right)$ and model probability $(w)$ for 5 models of age and feeding effects on mysid cohort survival

\begin{tabular}{|lccrc|}
\hline Model & $\log L$ & $k$ & $\Delta \mathrm{AIC}_{\mathrm{c}}$ & $W$ \\
\hline Age & -371.0 & 3 & 0.0 & 0.62 \\
Age + Feeding & -370.9 & 4 & 1.9 & 0.24 \\
Age $\times$ Feeding & -370.5 & 5 & 3.0 & 0.14 \\
Intercept & -381.4 & 2 & 18.8 & 0.00 \\
Feeding & -381.3 & 3 & 20.7 & 0.00 \\
\hline
\end{tabular}

to 0.91 between the highest and lowest feeding rates. In the cohort-based LTRE, constructed using substitution of these vital rates into matrix models, projected population-level response was overwhelmingly governed by feeding effects on fecundity (see next section). Analysis of size-at-age data from the cohort study indicated strong effects of feeding rate on growth $(\triangle \mathrm{AIC}=287$ for the 'no effects' model; Fig. 2).

\section{Population experiments}

We found strong evidence for feeding rate effects on adult survival $(P)$ in our population experiments (Table 3). Specifically, a logit-linear effect of feeding rate on $P$ appeared in the 6 best-supported models. These 6 models account for $96 \%$ of the total $\mathrm{AIC}_{\mathrm{C}}$ weights for the set of 28 models. In addition, 3 of the 


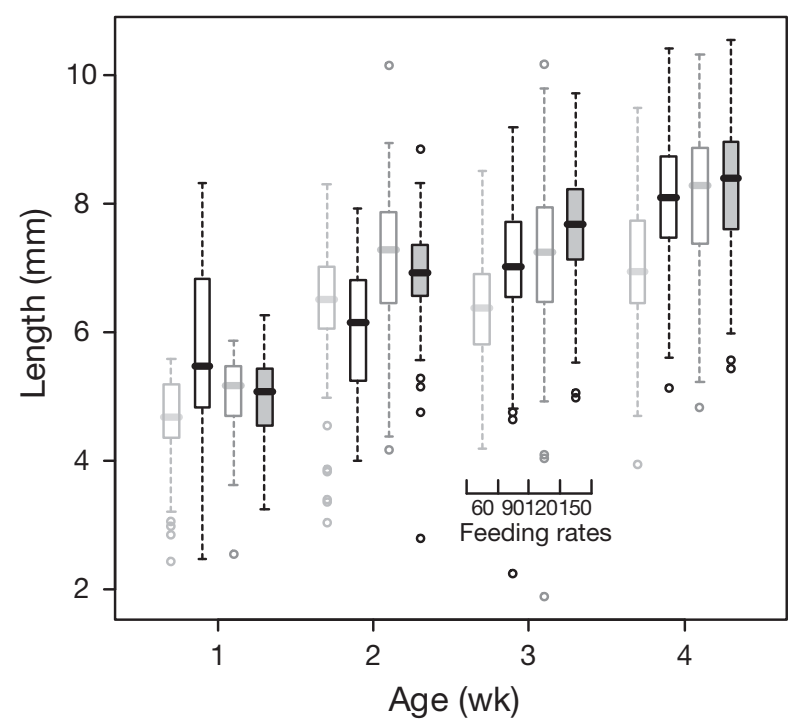

Fig. 2. Americamysis bahia. Individual mysid lengths measured weekly in cohorts maintained at 4 different feeding rates (Artemia mysid ${ }^{-1} \mathrm{~d}^{-1}$ ). Boxes for each treatment are offset horizontally to reveal treatment differences at each age. Lengths were taken from cohorts of 25 individuals of known age per aquarium ( 4 aquaria per feeding rate)

top 4 models contained feeding effects on 2 vital rates ( $P$ and $\gamma_{1}, P$ and $\gamma_{2}$, and $P$ and $F$ ). There was no support for any of the age-based models (i.e. where maturation rates $\gamma_{1}$ and $\gamma_{2}$ were constrained to one). Population projections incorporating model-averaged vital rates were better at predicting one-step transitions for adult abundance than for neonate or juvenile abundance, but residuals for all stages were symmetrically and narrowly distributed around zero (Fig. 3).

Based on LTRE calculations from model-averaged vital rates (Table 4), responses were overwhelmingly governed by feeding rate effects on adult survival (Fig. 4). Although the proportional effect of feeding on adult survival was small, sensitivity to this rate is high and magnifies the small change into a large effect on population growth rate $(\lambda)$. Other interpretations are more complex because vital rate contributions were computed as the product of sensitivity and vital rate response. Although the response of neonate maturation $\left(\gamma_{1}\right)$ was positive, the contribution of this response to $\lambda$ was negative due to negative sensitivity $\left(\partial \lambda / \partial \gamma_{1}<0\right)$. For juvenile maturation $\left(\gamma_{2}\right)$, both sensitivity and feeding effects were negative, so the contribution to fitness was positive. Moreover, the relatively small feeding effect on neonate maturation produced bigger changes in population growth rate than the larger changes in juvenile maturation (Table 4, Fig. 4). Nonetheless, the overall contribution of $P$ was 7 times larger than the absolute magnitude of all other contributions combined (Fig. 4). Overall, the differences in
Table 3. Americamysis bahia. Log-likelihood ( $\log L)$, number of parameters $(k)$, corrected AIC $\left(\Delta \mathrm{AIC}_{\mathrm{c}}\right)$ and model probability $(W)$ for 28 stage- and age-based models with varying treatment constraints on vital rates $\left(G_{1}, G_{2}, F\right.$ and $P$ ) in mysid population experiments. For example, Stage: $P_{r} F$ is a stagebased model that treats adult survival $(P)$ and fecundity $(F)$ as functions of feeding rate whereas all other vital rates are constant across treatments. There were 6 replicate populations for each of the 4 feeding treatments. Although denoted differently in age-based models for clarity, survival in the agebased models $\left(G_{i}\right)$ was parameterized as $S_{i} \gamma_{i}$ with $\gamma_{i}$ fixed at 1 to allow model averaging. $S_{i}$ : total survival for stage $i_{\text {; }}$ $\gamma_{i}$ : proportion of these survivors that transition into next stage

\begin{tabular}{|lcccc|}
\hline Model & $\log L$ & $k$ & $\Delta$ AIC & $W$ \\
\hline Stage: $P, \gamma_{2}$ & -349.4 & 14 & 0.0 & 0.28 \\
Stage: $P$ & -350.7 & 13 & 0.4 & 0.23 \\
Stage: $P, \gamma_{1}$ & -349.7 & 14 & 0.6 & 0.21 \\
Stage: $P, F$ & -350.5 & 14 & 2.3 & 0.09 \\
Stage: $P, S_{2}$ & -350.7 & 14 & 2.6 & 0.08 \\
Stage: $P, S_{1}$ & -350.7 & 14 & 2.6 & 0.08 \\
Stage: $S_{2}$ & -353.3 & 13 & 5.6 & 0.02 \\
Stage: $F_{1} S_{2}$ & -353.3 & 14 & 7.8 & 0.01 \\
Stage: $S_{2}, \gamma_{2}$ & -353.3 & 14 & 7.8 & 0.01 \\
Stage: $r e d u c e d$ & -356.2 & 12 & 9.2 & 0.00 \\
Stage: $F, \gamma_{1}$ & -354.6 & 14 & 10.4 & 0.00 \\
Stage: $S_{1}, \gamma_{1}$ & -354.7 & 14 & 10.6 & 0.00 \\
Stage: $\gamma_{2}$ & -356.1 & 13 & 11.2 & 0.00 \\
Stage: $F$ & -356.3 & 13 & 11.5 & 0.00 \\
Stage: $F_{1} \gamma_{2}$ & -356.1 & 14 & 13.4 & 0.00 \\
Stage: $F_{1} S_{1}$ & -356.3 & 14 & 13.8 & 0.00 \\
Stage: $\gamma_{1}$ & -358.2 & 13 & 15.3 & 0.00 \\
Stage: $S_{1}$ & -359.8 & 13 & 18.7 & 0.00 \\
Age: $P, F$ & -547.4 & 12 & 391.7 & 0.00 \\
Age: $F, G_{2}$ & -549.2 & 12 & 395.3 & 0.00 \\
Age: $P$ & -551.0 & 11 & 396.5 & 0.00 \\
Age: $P, G_{2}$ & -550.9 & 12 & 398.6 & 0.00 \\
Age: $G_{2}$ & -552.1 & 11 & 398.7 & 0.00 \\
Age: $P, G_{1}$ & -551.0 & 12 & 398.7 & 0.00 \\
Age: $F, G_{1}$ & -552.0 & 12 & 400.8 & 0.00 \\
Age: $F$ & -554.3 & 11 & 403.1 & 0.00 \\
Age: $r e d u c e d$ & -555.7 & 10 & 403.7 & 0.00 \\
Age: $G_{1}$ & -555.4 & 11 & 405.5 & 0.00 \\
& & & & \\
\hline
\end{tabular}

vital rate contributions between the cohort-based and population approaches are due to differences between the vital rate responses estimated from the experiments as well as differing demographic sensitivities of the 2 models constructed from these vital rates.

\section{DISCUSSION}

Our population experiments led to different conclusions about resource effects than those derived from the cohort experiments. This result is important for efforts to predict ecological effects of environmental stressors. Had we been equipped with cohort-based results only, the commonly used approach of matrix element substitution and the subsequent LTRE would 


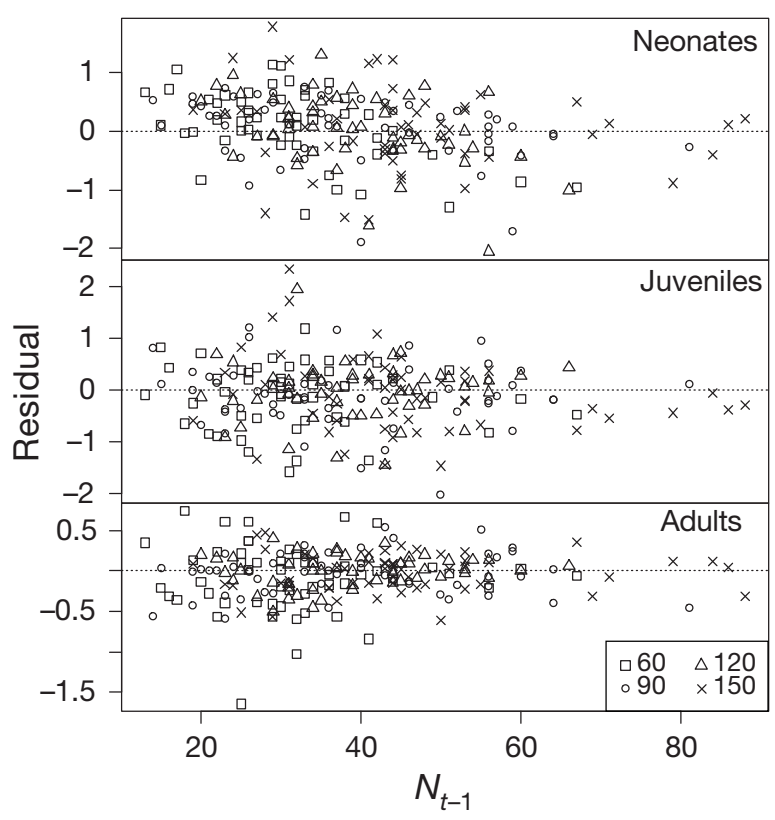

Fig. 3. Americamysis bahia. Residuals for mysid neonates, juveniles and adults versus total population size $(N)$ in population experiments. Residuals for a given stage and time are the log of the observed abundance of that stage minus the log of the expected stage abundance. Expected abundances are elements in the one-step projection of the population vector from the previous time step $\left(\mathbf{n}_{i, j, t-1}\right)$ using the model-averaged parameters to construct the estimate of matrix $\mathbf{A}_{j}$. Symbols denote feeding rates (Artemia mysid ${ }^{-1} \mathrm{~d}^{-1}$ ). Note differing scales on $y$-axes to reveal spread of points

Table 4. Americamysis bahia. Vital rate estimates from mysid cohort and population experiments with controlled feeding rates. Estimates for the population experiment are $\mathrm{AIC}_{\mathrm{c}}$ weighted model averages from a set of 28 models that included both age- and stage-based formulations. The cohort method did not allow construction of stage-based formulations, so the growth transition probabilities $(\gamma)$ are not included in the models. Feeding treatments increase from a to $d$, but have different meaning for cohort and population experiments in terms of Artemia per mysid because mysid density was controlled in the cohort experiments. See Table 3 for definition of parameters

\begin{tabular}{|c|c|c|c|c|}
\hline \multirow[t]{2}{*}{ Vital rate } & \multicolumn{4}{|c|}{ Feeding treatment } \\
\hline & $\mathrm{a}$ & $\mathrm{b}$ & $\mathrm{C}$ & d \\
\hline \multicolumn{5}{|c|}{ Cohort experiment } \\
\hline$G_{1}$ & 0.9734 & 0.9720 & 0.9706 & 0.9691 \\
\hline$G_{2}$ & 0.9597 & 0.9577 & 0.9555 & 0.9533 \\
\hline$F$ & 0.1435 & 0.2686 & 0.5027 & 0.9407 \\
\hline$P$ & 0.9393 & 0.9364 & 0.9332 & 0.9300 \\
\hline \multicolumn{5}{|c|}{ Population experiment } \\
\hline$S_{1}$ & 0.9997 & 0.9997 & 0.9997 & 0.9997 \\
\hline$\gamma_{1}$ & 0.1836 & 0.1877 & 0.1921 & 0.1968 \\
\hline$S_{2}$ & 0.9921 & 0.9966 & 0.9980 & 0.9984 \\
\hline$\gamma_{2}$ & 0.4937 & 0.4820 & 0.4704 & 0.4589 \\
\hline$F$ & 0.0404 & 0.0401 & 0.0398 & 0.0395 \\
\hline$P$ & 0.7088 & 0.7551 & 0.7960 & 0.8313 \\
\hline
\end{tabular}

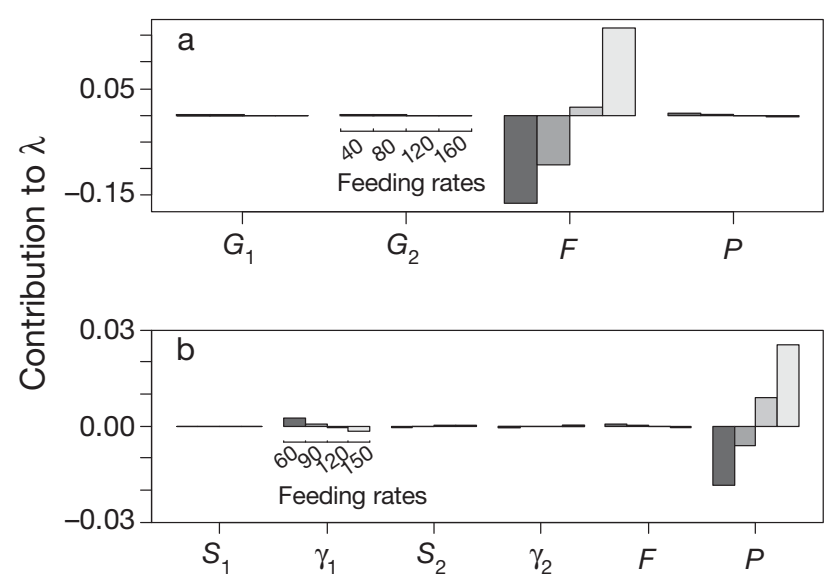

Fig. 4. Americamysis bahia. Contributions of feeding effects to mysid population growth based on life table response analysis of estimates from (a) cohort and (b) population experiments. $G_{1}$ and $G_{2}$ are survival rates for the age-based model used in the cohort analysis. $S_{1}$ and $\gamma_{1}$ are total survival and maturation rates for neonates ( $S_{2}$ and $\gamma_{2}$ are for juveniles), $F$ is adult fecundity and $P$ is adult survival. Maturation rates appear only in the stage-based model; the age-based model was formulated from Eq. (1) by constraining the $\gamma$ in Eq. (2) to one. Bars are computed as in life table response experiments (Caswell 2001) and are approximately the products of treatment effects and sensitivity of $\lambda$ to perturbations of each demographic rate (e.g. $\left.\partial \lambda / \partial S_{1}\right)$. Units for feeding rates are Artemia mysid ${ }^{-1} \mathrm{~d}^{-1}$

have led us to conclude that fecundity was by far the most biologically sensitive parameter and that fecundity impairment would contribute strongly to population dynamics in the presence of resource limitation (Fig. 4). The population experiments, however, indicated that adult survival and, potentially, growth of immature individuals were more sensitive to resource limitation and contributed most strongly to population response. Moreover, our population study suggests that stage-based models, which allow effects on maturation in addition to survival and fecundity, are superior to age-based models for laboratory populations of Americamysis bahia. Raimondo \& McKenney (2005) used stage-based formulations because of evidence for stressor effects on brood release timing in their cohort observations. Further comparison of their model projections with our observations of intact populations would be difficult because of the need to discriminate between multiple adult stages in their model, but their use of stage-based models is supported by our results.

Our cohort results comport with those of Kuhn et al. (2001), where reproduction by cohorts was more sensitive to toxicants than were other vital rates. In addition, Raimondo \& McKenney (2005) used LTRE decomposition analysis of their cohort results and, as in our cohort study, reported that fecundity was the driver of population response to sublethal stressor concentrations. 
By comparing cohort-based and population-based experiments, we do not mean to imply that the presence of mixed ages was the only distinguishing feature. Rather, our main conclusion is that there are myriad inherent differences between cohort and population studies that suggest they should be seen as complimentary rather than interchangeable. Some of these differences are the result of practical constraints on each type of experiment and the ecological processes that they eliminate or obscure. Our analyses of maturation rate serve as a good example. The importance of maturation to population dynamics was detectable only in our population study, but the need to examine maturation arose from the cohort observations of size at age. As an alternative to the population experiment, we could have obtained individual lengths for stagebased models by observing survival and fecundity of individuals reared in isolation. This labor- and spaceintensive approach might have enabled us to detect the importance of maturation without using intact populations. However, the potential effects of competition and cannibalism, both of which were likely important in the population experiments, would have been eliminated in this individual-based approach. We suspect that such an experiment and the associated stagebased models would have yielded yet another interpretation of resource effects. Of these various approaches, we see the observation of intact populations as the one most likely to yield insights about populations in the field.

There was a striking difference in fecundities estimated from the cohort and population experiments. Although fecundity was strongly affected by feeding rate in the cohort study, the lowest estimate (0.14) was still $>3$ times higher than the highest estimate in the population study (0.04). By comparison, Raimondo \& McKenney's (2005) highest daily fecundity estimate translates to a weekly estimate of approximately 0.08 , assuming their maternity estimate is total offspring per female. Kuhn et al. (2001) reported much higher daily rates ( $>5$ if translated to a weekly basis). This may be partly explained by the longer light cycle used in that study (16 vs. $\left.12 \mathrm{~h} \mathrm{~d}^{-1}\right)$. Also, daily counting and removal of offspring in that study would be expected to reduce the effects of cannibalism on fecundity estimates. In our study, where young were counted weekly instead of daily, cannibalism may have reduced fecundity estimates. Although not presented, there was a strong negative correlation between adult abundance and the number of neonates at the subsequent time step in our population experiments. Competition for food between adults or between adults and neonates is another plausible mechanism, but is unlikely because per capita food supply was evened out across feeding treatments by changes in abun- dance. At the same time, such changes in abundance within a fixed volume of space would increase encounter rates and opportunities for cannibalism, which is known to occur in laboratory populations of Americamysis bahia (Lussier et al. 1988). This interpretation would be consistent with the support we found for positive effects of resources on adult survival and a lack of observable benefits to neonate production in our population experiment.

Matrix element substitution has been used successfully with Americamysis bahia to predict trends in total population size in response to specific vital rate impairments (Kuhn et al. 2001). However, verification that the focal vital rate impairment is the underlying cause of the population response has been hindered by difficulties in estimating vital rates within intact populations. Establishing this mechanistic basis is crucial for linking biological knowledge from organism- and cohort-based studies to population-level effects. Ecologists will be tempted, for example, to substitute stress-response curves from ocean acidification studies into matrix models in order to explore ecological effects. Because most of these stress responses are from studies of individuals, cohorts or early life stages (see studies reviewed in Dupont et al. 2010, Hendriks et al. 2010), attempts to generalize results to population-, community- or ecosystem-level effects require caution. Our results demonstrate that methods now exist for grounding these generalizations in observations of real populations in controlled settings, potentially with close links to field settings where time series observations of stage abundances may be relatively easy to obtain. This conclusion is relevant for many taxa, but especially for mysids because the paucity of ecological data from field settings and intact populations is not proportionate with the abundance and diversity of mysids throughout the world's oceans and their potential importance in marine food webs (reviewed in Jumars 2007).

Much current work in population ecology focuses on the need to model complex processes with limited data and emphasizes small or endangered populations where resource limitation may be unimportant (Morris \& Doak 2002). Chemical risk assessors, however, are concerned with both small and large populations. As in the case of ocean acidification and other broad-scale marine stressors, the challenge is often to extrapolate results from a small suite of well-studied species to a huge diversity of populations and ecosystems where the influence of complexities such as resource availability may not be so easily ignored. For this reason, our work on zooplankton populations tries to strike a balance between rigid experimental control and ecological relevance. Our estimation method loses some of the mechanistic transparency of cohort approaches 
that will continue to be crucial, but also gains improved perspective on how intact populations of marine crustaceans may respond to stressors.

Acknowledgements. We thank J. Nye, S. Raimondo and A. Oczkowski for comments on an early version of the manuscript. K. McKeton, I. Kirby, E. Perkins, J. Pierce and P. Hackett also assisted in this work. This is contribution number AED-10-066 of the Atlantic Ecology Division, National Health and Environmental Effects Research Laboratory, Office of Research and Development, US Environmental Protection Agency (EPA). Although the research described in this article was funded by the EPA, it has not been subjected to agency review and does not necessarily reflect the views of the agency.

\section{LITERATURE CITED}

Burnham KP, Anderson DR (2002) Model selection and multimodel inference. Springer, New York, NY

Caswell H (1989) Analysis of life table response experiments. I. Decomposition of effects on population growth rate. Ecol Model 46:221-237

Caswell H (2001) Matrix population models: construction, analysis and interpretation. Sinauer Associates, Sunderland, MA

Dennis B, Desharnais RA, Cushing JM, Constantino RF (1995) Nonlinear demographic dynamics: mathematical models, statistical methods, and biological experiments. Ecol Monogr 65:261-281

> Dupont S, Ortega-Martinez O, Thorndyke M (2010) Impact of near-future ocean acidification on echinoderms. Ecotoxicology 19:449-462

Fabry VJ, Seibel BA, Feely RA, Orr JC (2008) Impacts of ocean acidification on marine fauna and ecosystem processes. ICES J Mar Sci 65:414-432

Forbes VE, Olsen M, Palmqvist A, Calow P (2010) Environmentally sensitive life-cycle traits have low elasticity: implications for theory and practice. Ecol Appl 20:1449-1455

Gentile JH, Gentile SM, Hairston NG, Sullivan BK (1982) The use of life-tables for evaluating the chronic toxicity of pollutants to Mysidopsis bahia. Hydrobiologia 93:179-187

Heard RW, Price WW, Knott DM, King RA, Allen DM (2006) A taxonomic guide to the mysids of the South Atlantic Bight. NOAA Professional Paper NMFS 4. NOAA, Silver Spring, $\mathrm{MD}$

Hendriks IE, Duarte CM, Alvarez M (2010) Vulnerability of marine biodiversity to ocean acidification: a meta-

Editorial responsibility: Nicholas Tolimieri,

Seattle, Washington, USA analysis. Estuar Coast Shelf Sci 86:157-164

Jumars PA (2007) Habitat coupling by mid-latitude, subtidal, marine mysids: import-subsidised omnivores. Oceanogr Mar Biol Annu Rev 45:89-138

Kuhn A, Bengtson DA, Simpson KL (1991) Increased production by mysids (Mysidopsis bahia) fed with enriched Artemia spp. nauplii. Am Fish Soc Symp 9:192-199

Kuhn A, Munns WR Jr, Poucher S, Champlin D, Lussier SM (2000) Prediction of population-level response from mysid toxicity test data using population modeling techniques. Environ Toxicol Chem 19:2364-2371

Kuhn A, Munns WR Jr, Champlin D, McKinney R, Tagliabue M, Serbst J, Gleason T (2001) Evaluation of the efficacy of extrapolation population modeling to predict the dynamics of Americamysis bahia populations in the laboratory. Environ Toxicol Chem 20:213-221

Lussier SM, Kuhn A, Chammas MJ, Sewall J (1988) Techniques for the laboratory culture of Mysidopsis species (Crustacea, Mysidacea). Environ Toxicol Chem 7:969-977

Lussier SM, Kuhn A, Chammas MJ, Sewall J (1991) Life history and toxicological comparisons of temperate and subtropical mysids. Am Fish Soc Symp 9:169-181

Markert JA, Champlin DM, Gutjahr-Gobell R, Grear JS and others (2010) Population genetic diversity and fitness in multiple environments. BMC Evol Biol 10:205

Mauchline J (1980) The biology of mysids and euphausids. Academic Press, London

Morris WF, Doak DF (2002) Quantitative conservation biology: theory and practice of population viability analysis. Sinauer Associates, Sunderland, MA

Raimondo S, McKenney CL Jr (2005) Projected populationlevel effects of thiobencarb exposure on the mysid, Americamysis bahia, and extinction probability in a concentration-decay exposure system. Environ Toxicol Chem 24: $564-572$

Rasband WS (2009) ImageJ. US National Institutes of Health, Bethesda, MD. Available at http://rsb.info.nih.gov/ij/

R Development Core Team (2008) R: a language and environment for statistical computing. R Foundation for Statistical Computing, Vienna

Ries JB, Cohen AL, McCorkle DC (2009) Marine calcifiers exhibit mixed responses to $\mathrm{CO}_{2}$-induced ocean acidification. Geology 37:1131-1134

SAS Institute (2008) The SAS System for Windows, Version 9.2. SAS Institute, Cary, NC

Verslycke T, Ghekiere A, Raimondo S, Janssen C (2007) Mysid crustaceans as standard models for the screening and testing of endocrine-disrupting chemicals. Ecotoxicology 16:205-219

Wood SN (1994) Obtaining birth and mortality patterns from structured population trajectories. Ecol Monogr 64:23-44

Submitted: December 8, 2010; Accepted: April 4, 2011 Proofs received from author(s): June 6, 2011 